\title{
O disco We Shall Overcome e a propagação de canções pró-direitos civis nos Estados Unidos.
}

\begin{abstract}
MARIANA OLIVEIRA ARANTES $S^{* *}$
RESUMO: O presente artigo analisa o disco We Shall Overcome. Songs of the "Freedom Riders" and the "Sit-ins", gravado em fevereiro de 1961 pela gravadora Folkways, na cidade de Nova Iorque. Com doze canções, sendo sete no lado A e cinco no lado B, interpretadas pelos grupos The Montgomery Gospel Trio e The Nashville Quartet e pelo cantor Guy Carawan, o disco apresenta uma parte do repertório utilizado durante os eventos relacionados ao movimento pelos direitos civis nos Estados Unidos. Nosso objetivo é compreender de que maneira distintas tradições culturais foram mobilizadas e reformuladas a fim de atenderem as demandas do movimento. Por meio da difusão de canções em diferentes suportes, como livros e discos, diversos artistas e mediadores contribuíram para a consolidação e legitimação de um cânon de canções, parte de uma determinada tradição cultural, que foi mobilizado em prol do mais influente movimento social do país.
\end{abstract}

PALAVRAS-CHAVE: Estados Unidos; música; movimento pelos direitos civis.

\section{The disc We Shall Overcome and the spread of civil rights songs in the United States.}

ABSTRACT: This article analyses the disc We Shall Overcome. Songs of the "Freedom Riders" and the "Sit-ins", recorded on April 1961 by Folkways Records, in New York city. It has twelve songs, seven in side I and five in side II, performed by The Montgomery Gospel Trio, The Nashoille Quartet and Guy Carawan. The disc shows a part of the repertoire used during the civil rights movement actions in the United States. We aim to comprehend in which way some cultural traditions were mobilized and redrafted to attend the demands of the movement. Through the diffusion of songs in different ways, like books and discs, a lot of artists and mediators helped the consolidation and legitimation of a canon of songs, integrating a specific cultural tradition that was mobilized towards the most influent social movement of the country.

KEYWORDS: The United States; music; civil rights movement.

\footnotetext{
* Este texto contém algumas ideias presentes em minha tese de doutorado intitulada Canto em marcha: música folk e direitos civis nos Estados Unidos (1945-1960), financiada pela Fundação de Amparo à Pesquisa do Estado de São Paulo - FAPESP e defendida em 2014 no Programa de Pós-graduação em História da UNESP/Franca.

** Mariana Oliveira Arantes é Doutora, Mestre, Bacharel e Licenciada em História pela Faculdade de Ciências Humanas e Sociais da Universidade Estadual Paulista "Júlio de Mesquita Filho", Campus de Franca, São Paulo, Brasil. E-mail: mel.unesp@gmail.com
} 
egistros que atestam as relações entre a história e a música, especificamente
o uso político da música, existem de longa data. Por sua capacidade de
atuar como fator de identificação e mobilização a música apresenta-se como um meio privilegiado para a expressão de "paixões políticas".

David King Dunaway em seu texto Folk Music, Politics, and the Urge to Sing Out, publicado em 2011, explica que muitos movimentos políticos colocaram a música a serviço de sua causa. Desde que os colonos desembarcaram na América, a música tem servido como um barômetro dos sentimentos políticos. $\mathrm{O}$ autor ainda acrescenta que tradições de dissenso popular, como as canções de cunho político, são universais à humanidade. "Cada cultura gera seus próprios meios de protesto social" (DUNAWAY, 2011, p. 03-04).

Especificamente sobre as tradições de dissenso nos Estados Unidos, Dunaway afirma:

Na América do Norte, uma das mais difundidas formas de dissenso tem sido a canção de protesto social. Em 1734, o rebelde compositor John Pete Zenger utilizou canções políticas com tanto sucesso em uma campanha eleitoral que, o então governador real de Nova Iorque, William Cosby, proclamou uma recompensa pela detenção do autor das 'escandalosas canções ou baladas'; e então queimou os ofensivos panfletos. Desde então, governantes e seus agentes têm perseguido cantores ${ }^{1}$ (2011, p.04).

Na história dos Estados Unidos, nenhum movimento político dotou a música de tanta importância como o movimento pelos direitos civis.

No início do século $\mathrm{XX}$ os movimentos sociais afro americanos que lutavam contra a segregação e linchamentos estavam intimamente identificados com uma determinada forma de expressão musical, o spiritual. Em 1903, o ativista político e intelectual afro americano Willian Eduard Burghardt Du Bois publicou seu influente livro intitulado As almas da gente negra, no qual afirma, a respeito dessa forma musical, que era a "mensagem articulada do escravo para o mundo" (DU BOIS, 1903).

Por meio de uma vida intelectual ativa, Du Bois tornou-se "reconhecido como o mais influente líder político na primeira metade do século $X X$, e quem mais explicitamente revelou para o mundo o impacto da opressão racial entre as

\footnotetext{
1 Tradução livre da autora.
} 
comunidades negras" (ABREU, 2015, p. 181). Na época do lançamento de As almas da gente negra Du Bois era professor de História e Economia da Universidade de Atlanta e, como afirmam as historiadoras Martha Abreu e Larissa Viana, essa era "uma região central do segregacionismo sulista" (ABREU; VIANA In: AZEVEDO; RAMINELLI, 2011, p.182). Assim, a valorização da música afro americana em diversas de suas publicações, especialmente no último capítulo dessa influente obra, demonstra que o autor dava muita importância aos sentidos políticos do repertório afro americano.

Martha Abreu, em seu texto O legado das canções escravas nos Estados Unidos e no Brasil: diálogos musicais no pós-abolição, realiza uma comparação entre a produção do brasileiro Coelho Neto e de Du Bois, afirmando:

Du Bois e Coelho Netto demonstram saber que escrever ou opinar sobre a música dos escravos, entre o final do século XIX e o início do XX, era avaliar - nos seus casos, positivamente - o legado cultural dos africanos e seus descendentes no imaginário das sociedades modernas, nacionais e pósescravistas. E avaliar a música negra, ou o legado da canção escrava, era também participar do debate e da crítica sobre a hierarquia das raças e sobre as possibilidades de integração dos descendentes de africanos. Suas palavras e avaliações são exemplos contundentes - e úteis - para destacarmos o poder do campo musical nesse momento de (re) definição de identidades raciais, sociais e nacionais - e vice-versa: as identidades sociais e raciais revestiramse de expressões musicais (ver Radano, 2003) (2015, p. 184).

Desse modo, desde o início do século XX, é possível apreender que as ações de grupos afro americanos contra a segregação e desigualdade racial nos Estados Unidos estiveram intimamente relacionadas à afirmação e valorização da cultura afro, com especial ênfase na música afro americana.

As primeiras músicas do movimento em prol de grupos afro americanos foram spirituals e gospels tradicionais utilizados nos cultos das igrejas. Grande parte das organizações e grupos militantes envolvidos nas lutas pelos direitos civis no Sul dos Estados Unidos mantinham estreitas conexões com as igrejas protestantes como a Batista, Metodista e Presbiteriana, que tinham uma forte tradição de interpretar canções spirituals. A música era parte das igrejas e comunidades afro americanas e, normalmente, era conduzida pelos ministros e grupos de canto coral, que interpretavam os spirituals com as letras e estilo tradicionais, com muitos improvisos e elementos característicos do gênero como o canto em coro, o acompanhamento com 
palmas e muitos melismas nas melodias. Assim, encontrar um song leader era tão importante quanto encontrar outros tipos de lideranças para o movimento.

As igrejas não só proporcionaram um repertório cultural, mas eram efetivamente um lugar de encontro para traçar estratégias e ações, ajudando a mobilizar o movimento. Como afirma William Roy em seu livro Reds, Whites, and Blues: social movements, folk music, and race in the United States, "as igrejas proveram um modelo de liderança, um senso de identidade e uma cultura de compartilhar símbolos e rituais" (2010, p.183).

Peter Goldsmith esclarece que, desde os boicotes de ônibus de Montgomery ocorridos a partir de 1955, os participantes das manifestações em prol dos direitos civis se aproximaram da música sacra afro americana com a convicção de tratar-se de um repertório de resistência. Sua estrutura, que permitia a improvisação, tornava-a altamente adaptável (GOLDSMITH, 1998). Assim, foram interpretados hinos com o acompanhamento do bater de palmas, danças, clamores e adoração por grupos como o Montgomery Gospel Trio ou o Nashville Quartet, que eram estudantes do American Baptist Theological Seminary.

Outra instituição historicamente ligada ao repertório musical afro americano eram as universidades negras. Além das canções religiosas, muitas canções da cultura estudantil eram seculares, principalmente hinos e blues. E muitas destas canções seculares tinham de ser adaptadas para serem utilizadas nas ações do movimento pelos direitos civis.

William Roy esclarece que nos anos 1940 a cantora Mahalia Jackson iniciou uma tendência interpretativa que transformou as canções de referências sacras em uma "música que podia ser cantada tanto na igreja quanto nas ruas, isso ajudou a inspirar os "freedom songs" que caracterizaram o movimento pelos direitos civis dos anos 1950 e começo de 1960” (2010, p.77). Tal afirmação vem ao encontro da assertiva publicada em outra obra dedicada ao estudo das relações entre a música e a política, o livro Music and social movements: mobilizing traditions in the twentieth century, dos autores Ron Eyerman e Andrew Jamison, de que quando o movimento pelos direitos civis foi expandido das comunidades locais para incluir outros 
segmentos populacionais, primeiro negros, depois brancos, a música também se abriu para novas referências (1998).

É importante destacar que o movimento pelos direitos civis foi um movimento descentralizado. As ações como os sit-ins (ocupações pacíficas), freedom rides $^{2}$, boicotes de ônibus e outras atividades começaram localmente e depois foram difundidos "por imitação entre redes estruturadas espontaneamente". Sobre essas "redes espontâneas" são esclarecedoras as palavras de William Roy:

\begin{abstract}
Organizações nacionais como a $\mathrm{SNCC}^{3}$, SCLC ${ }^{4}$ e CORE $^{5}$ foram primeiramente federações autônomas locais, e serviram para facilitar a difusão de eventos, melhorar a comunicação entre os ativistas, e prover porta-vozes para a mídia nacional. A música foi propagada pelo movimento da mesma forma que as atividades - através de difusão e redes informais, com as organizações nacionais desempenhando um papel de coordenação, mais do que de direção por decreto (2010, p. 210-211).
\end{abstract}

Ou seja, a música circulava entre as organizações e instituições militantes pelos direitos civis de afro americanos porque as pessoas circulavam, levando e trazendo referências culturais a serem mobilizadas em prol da causa. Muitos foram os mediadores responsáveis por ajudar a criar um elo comum entre as atividades de cada comunidade.

Uma das personagens mais atuantes na divulgação de um repertório a ser utilizado nas manifestações, encontros e demais ações do movimento foi o cantor e compositor branco Guy Carawan. O intérprete nasceu na Califórnia, em 1927, passou a infância em Los Angeles, onde a mãe o enviou para estudar em uma escola pública fora de seu bairro, para que ele não tivesse que estudar com crianças afro americanas da sua vizinhança. Suas primeiras experiências com a música se resumiram ao clarinete e as canções da banda marcial da Legião Americana. Enquanto estudava

\footnotetext{
$2 \mathrm{O}$ termo freedom rides, traduzido como viagens ou viajantes da liberdade, refere-se às viagens organizadas pelo Congresso da Igualdade Racial (CORE) a partir de 1961 que transportavam afro americanos e brancos nortistas em direção ao Sul dos Estados Unidos em ônibus interestaduais, a fim de simbolizar a integração em transportes públicos.

3 Student Nonviolent Coordinating Committee - SNCC, traduzido como Comitê Sulista de Coordenação Não Violenta, organização criada por estudantes e ativistas pelos direitos civis na Shaw University, na Carolina do Norte, em abril de 1960.

${ }^{4}$ Southern Christian Leadership Conference - SCLC, traduzido como Conferência da Liderança Cristã do Sul, organização criada por ativistas pelos direitos civis em 1957 em Atlanta.

${ }^{5}$ Congress of Racial Equality - CORE, traduzido como Congresso da Igualdade Racial, organização criada por ativistas pelos direitos civis em $1942 \mathrm{em}$ Chicago.
} 
Matemática no Occidental College, aprendeu a tocar ukulele e conheceu o professor Bill Oliver, membro da People's Song 6 de Los Angeles, que o apresentou a outros membros da organização.

Carawan conheceu o intérprete e compositor Pete Seeger quando estava terminando seu mestrado em Sociologia na Universidade da Califórnia, em Los Angeles, com quem acabou aprendendo a maior parte de seu repertório engajado.

Após a morte da diretora musical da Highlander Folk School, Zilphia Horton, Carawan foi convidado para assumir seu cargo, em 1956. Depois que se tornou diretor da Highlander Folk School intensificou seu engajamento e passou a atuar intensamente no movimento pelos direitos civis, junto a líderes de diversas organizações.

A Highlander Folk School7 foi criada em 1932, em New Market, Tennessee, por Miles Horton e Don West, com o objetivo de amparar iniciativas dedicadas à educação de homens e mulheres ligados ao movimento trabalhista do país, mantendo estreitas conexões com o $\mathrm{CIO}^{8}$. Nos anos 1950, com o clima anticomunista aflorado, muitos sindicatos afastaram-se da escola, pois temiam serem identificados com sua ideologia de esquerda. Assim, os diretores da escola decidiram que seus esforços seriam direcionados à luta contra o racismo no país, disponibilizando o local para reuniões, palestras, cursos, com material de apoio, como a biblioteca, para as organizações que lutavam pela causa dos direitos civis.

Os diretores da escola trabalharam junto a sindicatos, fazendeiros, grupos comunitários, igrejas e organizações dos direitos civis.

A Highlander Folk School realizou uma série de workshops chamados de Sing for Freedom, com a intenção de ensinar um repertório a ser utilizado nos atos do movimento, bem como ensinar como utilizar a música em manifestações, vigílias, caminhadas e encontros.

\footnotetext{
${ }^{6}$ Organização criada em Nova Iorque em 1945 por personagens ligados à música folk dos Estados Unidos como Pete Seeger, Alan Lomax, Lee Hays e outros. A organização publicou uma revista homônima de 1946 a 1950. Para mais informações ver ARANTES, 2014.

${ }^{7}$ Em 1963 seu nome foi mudado para Highlander Folk Center.

8 Congress of Industrial Organizations - CIO, traduzido como Congresso das Organizações Industriais, central sindical alternativa à Federação Americana do Trabalho - AFL, fundada em 1935 por John L. Lewis, presidente da United Mine Workers, e líderes de mais sete sindicatos ligados à AFL.
} 
Sobre a atuação de Guy Carawan junto a Highlander Folk School concordamos com as afirmações de William Roy:

Comprometido com a ideia de que o movimento deveria "soar como um movimento", Carawan promoveu uma música com uma base folk e religiosa, ou seja, músicas as quais as conotações musicais e líricas significavam retidão moral e autenticidade cultural. Enquanto as paródias de canções de rock and roll sementavam um senso de união, Carawan ajudou a criar um novo gênero - freedom songs - que expressava a associação do movimento à Cristandade, e, como uma forma de spiritual, sua herança afro americana e raízes na cultura escrava (2010, p. 168).

O papel de Carawan, de sua esposa e da Highlander Folk School como grandes articuladores do movimento musical intrínseco ao movimento pelos direitos civis é reconhecido na bibliografia sobre o tema dos direitos civis. Candie Anderson, (depois Candie Carawan), era estudante da Fisk University e militante das manifestações ocorridas na cidade de Nashville, durante as quais conheceu Guy.

A função de Guy Carawan como diretor musical da Highlander Folk School era exatamente participar das reuniões, palestras, cursos e eventos das organizações ligadas ao movimento pelos direitos civis, ensinando canções e interpretando-as durante as manifestações e, sempre que possível, compor novas canções que contribuíssem com a causa.

Como grande parte dos militantes das manifestações, Guy e sua esposa foram presos diversas vezes, uma delas foi durante um workshop com líderes dos direitos civis na Highlander, quando a policia local apareceu, procurando por provas da venda ilegal de bebidas alcoólicas, e encontrou uma pequena quantidade de whisky na casa de Miles Horton, diretor da escola. Os envolvidos afirmam que tais provas foram plantadas pela polícia no local, como motivo para a prisão de Septima Clark, Guy Carawan e outros.

Ao longo dos anos de 1960 o casal viajou pelo Sul do país, acompanhando as manifestações e documentando-as, por meio de gravações e transcrições das canções interpretadas durante tais eventos. Tal repertório foi publicado nos livros We shall overcome! Songs of the Southern Freedom Movement, lançado em 1963, e Freedom is a Constant struggle: Songs of The Freedom Movement, publicado em 1968.

A compilação de Carawan, We shall overcome! Songs of the Southern Freedom Movement, foi publicada por Moses Asch e Irwin Silber na Oak Publications, com 
canções agrupadas por fases do movimento. A grande maioria das canções evoca o compromisso com a liberdade, a vitória ou o movimento de maneira difusa. "Menos da metade faz alguma referência à segregação, integração ou Jim Crow ${ }^{9 \prime \prime}$ (ROY, 2010, p.206).

Guy e Candie Carawan também lançaram discos contendo o material compilado enquanto acompanhavam as atividades de diversas organizações militantes no movimento pelos direitos civis. Em 1961 lançaram o disco Freedom in the air: Albany Georgia, pela gravadora Vanguard, produzido por Guy Carawan e Alan Lomax, com canções utilizadas pelo Student Nonviolent Coordinating Committee SNCC, nos protestos em Albany. Em 1980 lançaram a coletânea Birmingham, Alabama, 1963: Mass Meeting, com falas de Martin Luther King Jr., Ralph Abernathy e o coral Birmingham Movement, entre outros.

Entre os materiais documentados pelo casal Carawan, percebemos que um repertório padrão foi gravado no disco We shall overcome. Songs of the "Freedom Riders" and the "Sit-ins", gravado em fevereiro de 1961 pela Folkways Records, produzido por Guy Carawan e Moses Asch, com designer de Ronald Clyne.

A gravadora Folkways foi criada no ano de 1948 por Moses Asch, com o objetivo de preservar e divulgar uma variedade de estilos e tipos de gravação, comprovando o que o próprio afirmava ter como missão: documentar toda possível expressão sonora e fazer uma enciclopédia do som. Ele era um engenheiro de gravação de formação, mas se auto intitulava um documentarista.

A Folkways foi responsável pela gravação de um catálogo expressivo do repertório folclórico, tornando-se uma referência no mercado musical estadunidense da segunda metade do século XX. O estadunidense Richard Carlin afirma que, com

\footnotetext{
9 De acordo com Martha Abreu e Larissa Viana a expressão Jim Crow teria "designado um personagem negro criado no mundo artístico e teatral por Thomas Darmouth "Daddy" Rice, um ator branco. O personagem estreou nos palcos de Nova York nas primeiras décadas do século XIX e, logo em seguida, recebeu aplausos das plateias de todo o país. O sucesso cômico do personagem era marcado por músicas e danças identificadas como típicas dos negros. As músicas eram conhecidas como Ethiopian melodies e os espetáculos como Coon shows (negro, crioulo). Jim Crow tornou-se até um reconhecido gênero artístico e comercial. [...] Após o período da Reconstrução Radical, em meio ao retrocesso dos direitos políticos e civis dos negros, a ridicularização artística, personificada em Jim Crow, serviu para denominar as diversas situações e o próprio período do segregacionismo racial" (In: AZEVEDO; RAMINELLI, 2011, p. 179-180).
} 
seu forte interesse na cultura afro americana, Moses Asch esteve entre os primeiros a reconhecer o crescimento do movimento pelos direitos civis e sua importância em transformar a vida política e social da América e muitos dos artistas que ele gravou foram os primeiros defensores dos direitos civis (2008, p. 214).

O disco We shall overcome contém doze canções, sendo sete no lado A e cinco no lado B, interpretadas pelos grupos The Montgomery Gospel Trio e The Nashville Quartet e pelo cantor Guy Carawan.

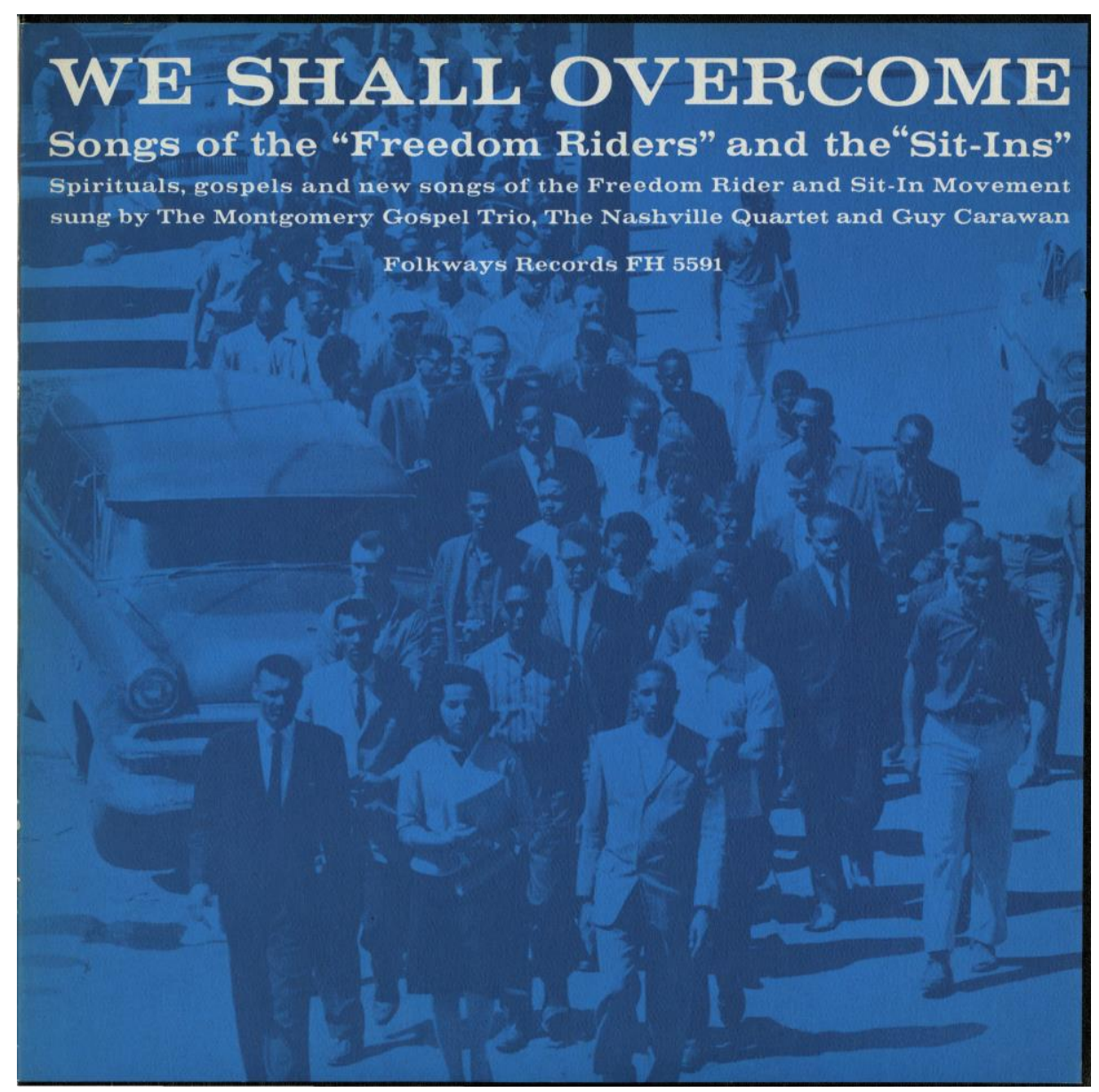

Ex. 1 - Foto da capa do disco We shall overcome. Songs of the "Freedom Riders" and the "Sitins".

The Nashville Quartet era um grupo vocal formado por Joseph Carter, Bernard Lafayette, James Bevel e Samuel Colier, quatro estudantes do American Baptist Theological Seminary na cidade de Nashville. Foram quatro militantes das ações do movimento, tendo sofrido diversos tipos de repressão, como a prisão. 
O Montgomery Gospel Trio também era um grupo vocal formado por Minnie Hendrick, Marie Ethel Dozier e Gladys Burnette Carter, três estudantes do ensino médio da cidade de Montgomery, no estado do Alabama, igualmente ativas militantes das ações do movimento pelos direitos civis.

O disco foi lançado pela Folkways acompanhado de um encarte no molde de um livreto, contendo seis páginas. Na primeira página os intérpretes são apresentados em um texto que destaca a intensa participação de todos em diversos atos do movimento, seguido de suas fotografias e da explicação de que o convite para a gravação do disco foi feito por Moses Asch quando os intérpretes estavam em Nova Iorque para fazer um show no Carnegie Hall junto com outros artistas, como Pete Seeger.

Após tais apresentações, há um texto explicativo sobre o movimento em si, sobre a luta dos estudantes pelo fim da segregação no Sul dos Estados Unidos, e sobre a dificuldade de convencer os mais velhos a se juntarem à causa nas ações diretas, sofrendo as consequentes repressões por parte do governo e de parte da sociedade branca. O texto enaltece a filosofia da desobediência civil não violenta utilizada pelo movimento, afirmando que "a coragem, disciplina e adorável comportamento dos participantes fez com que eles ganhassem o respeito e o interesse de muitas pessoas à sua causa" (WE SHALL OVERCOME, p. 03). E, além da filosofia e métodos empregados pelos participantes das ações do movimento, os estudantes afro americanos são exaltados como verdadeiros exemplos a serem seguidos:

\footnotetext{
Eles, muito eficazmente, dramatizaram perante suas comunidades, o país e o mundo que eles não mais aceitarão "cidadania de segunda classe" nesta "terra da liberdade e lar da coragem". Eles, de uma vez por todas, acabaram com o estereótipo sulista e refutaram a ideia de que os negros são felizes com a segregação (WE SHALL OVERCOME, p.02).
}

Após os textos, foram publicadas as letras das doze canções que compõem o disco. Os textos são entrecortados por seis fotografias em preto e branco de momentos marcantes do movimento pelos direitos civis, como Martin Luther King falando para 4.000 pessoas em uma reunião do movimento. 


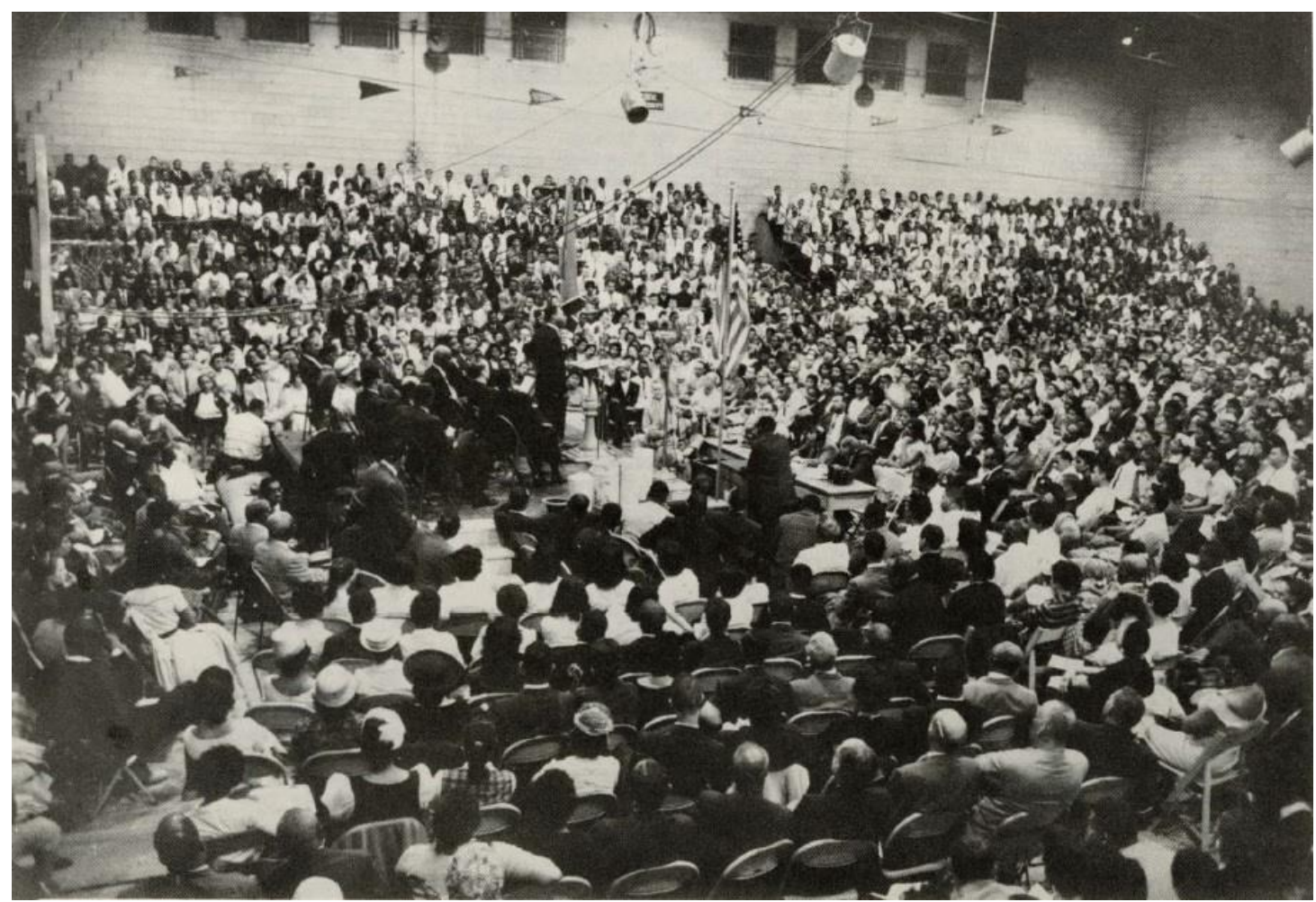

Ex. 2 - Foto do encarte do disco We shall overcome. Songs of the "Freedom Riders" and the "Sit-ins", p.04.

Onze das doze canções do disco são spirituals e gospels gravados em uma única sessão de gravação no estúdio da Folkways, com as melodias entoadas apenas com o acompanhamento de um violão. Acredito que neste disco está claramente presente uma forma canônica de canções utilizadas na primeira fase do movimento pelos direitos civis, entenda-se até meados da década de 1960: versos curtos repetidos que facilitam a introdução de novos versos, ritmo forte, convidativo às palmas, formato de canto de Chamado e Resposta.

A maioria dessas canções pode ser considerada zipper songs, termo utilizado nos Estados Unidos para canções nas quais a maioria dos versos continua o mesmo cada vez que se canta, havendo a substituição de algumas palavras ou frases inteiras, como em muitos hinos afro americanos. Pela facilidade de aprendizagem rápida e possibilidade de repetição por um longo período de tempo, este tipo de canção é apropriada para o canto em coro, como em muitas manifestações pelos direitos civis.

As canções do disco We shall overcome estão entre as mais conhecidas e cantadas durante todos os tipos de mobilizações do movimento, desde as maiores 
como sit-ins, viagens da liberdade e marchas, como atividades com um menor número de pessoas como reuniões e workshops. Todas são canções frequentemente citadas por pessoas que participaram de algum ato, em entrevistas e publicações posteriores, com uma enorme quantidade de versões gravadas. São elas: Lado A - 1"This little light of mine", 2- "There's a meeting here tonight", 3- "Rock my soul", 4"Hold on", 5- "Let us break bread together", 6- "We are soldiers in the army", 7- "We shall not be moved", Lado B - 1- "Your dog", 2- "Michael row the boat ashore", 3 "I'm so glad", 4 - “Oh freedom" e 5 - "We shall overcome".

A única canção que não é um antigo spiritual, ou uma adaptação de algum deles, é "Your dog", composta por James Bevel e Bernard Lafayette, dois integrantes do Nashville Quartet. Bevel deu o seguinte depoimento no livro organizado por Pete Seeger e Bob Reiser, Everybody says freedom: a history of the Civil Rights Movement in songs and pictures:

Eu vivia na porta ao lado de um homem e ele tinha muitos filhos, assim como meu pai, mas nós não éramos permitidos de brincar juntos porque eles eram brancos. Mas, nós tínhamos dois cachorros. Ele tinha um cachorro e nós tínhamos um cachorro. Nossos cachorros sempre podiam brincar juntos... Assim, eu fiz essa canção para o nosso grupo, o Nashville Quartet (BEVEL In: SEEGER; REISER, 1989, p. 44).

E assim, a canção, interpretada a capela com harmonizações a muitas vozes, inicia entoando "my dog loves your dog, your dog loves my dog" (meu cachorro ama seu cachorro, seu cachorro ama meu cachorro). E, em um verso mais ao final, clama "You won't walk with me, You won't talk with me. Why don't you hold my hand, So we can understand?" (Você não andará comigo, Você não falará comigo. Por que você não segura minha mão, Então nós podemos nos entender?). Por mais que o ritmo não seja o mesmo das demais canções gravadas no disco, uma vez que essa é muito mais ritmada e de andamento mais rápido, e com harmonizações mais sofisticadas, a temática continua sendo a mesma, a integração racial no país.

A canção que finaliza e dá nome ao disco, "We shall overcome”, é um tradicional spiritual cantado em coro e com uma letra modificada, a fim de expressar os sentimentos de luta, esperança e perseverança do movimento.

Peter Goldsmith afirma que os spirituals são maleáveis e suas letras podem ter diversas interpretações. $\mathrm{O}$ autor chama a atenção para o fato de que não 
faz sentido discutir se os spirituals são apenas sagrados ou também tratam de coisas terrenas e profanas se levarmos em consideração as crenças religiosas africanas, que não fazem essa distinção entre o que é sagrado e profano, celeste e terreno, pois não distinguem a vida em uma esfera sobrenatural e outra natural (GOLDSMITH, 1998).

Tais assertivas de Goldsmith estão em acordo com as convicções de Du Bois defendidas em as Almas da gente negra em 1903, quando o autor trata do repertório de canções afro americanas atribuindo-lhe um papel político de resistência e perseverança, como no excerto final da obra:

Transpassando todo o padecimento que se contém nas sorrow songs (canções de sofrimento) existem espasmos de esperança e uma fé na justiça derradeira das coisas. As cadências suaves de desespero mudam, geralmente, para acordes de triunfo e serena confiança. Às vezes, é a fé na vida, noutras, é a fé na morte, algumas vezes é a segurança de uma justiça sem fronteiras num mundo justo lá adiante. Mas seja como for o significado é sempre claro que um dia, nalgum lugar, o homem julgará seu semelhante pela sua alma e não pela cor de sua pele (DU BOIS, p.225).

O corpus de canções utilizadas no movimento pelos direitos civis afirmava o orgulho afro americano, mas é importante aclarar que nem todas as canções podem ser consideradas estritamente afro americanas, sendo mais uma cultura de um movimento racialmente inclusivo, "uma ponte entre raças erigida por ativistas negros e brancos trabalhando juntos" (ROY, 2010, p.170).

A respeito da origem da canção "We shall overcome", concordo com Hardeep Phull, em sua obra Story behind protest song, quando afirma que, por tratarse de uma canção folclórica, foi alterada e adaptada a diversas performances. Em suas palavras:

Na verdade, definitivamente, não há como responder de onde ela realmente veio, todavia, há um consenso entre acadêmicos da Música e da História sobre a autoria do reverendo Charles Tindley, um ministro da Filadélfia, nascido de pais escravos, em 1851. Tindley também compôs outras canções religiosas, uma delas chamava-se "I'll overcome some day" e foi publicada pela primeira vez em 1901. Ele baseou a determinação de sua letra no verso dos Gálatas 6:9 da Bíblia, que implora aos crentes que não se cansem em suas boas ações, que eles acabarão por colher recompensas. Embora Tindley tenha escrito sua própria melodia para a canção, ela gradualmente sofreu adaptações de diferentes melodias ao longo de sua difusão - mais notadamente a de um antigo spiritual dos escravos chamado "I'll be all right", que por sua vez parece ter tido sua melodia tirada de um hino europeu datado do final do século XVIII, chamado "O Sanctissima" (2008, p.01). 
Em 1946, Pete Seeger aprendeu a canção "We Will overcome" com Zilphia Horton, publicando-a na revista People's Song no mesmo ano. Em 1945, Zilphia havia escutado a canção em um piquete de greve dos trabalhadores negros das indústrias de tabaco em Charleston, Carolina do Sul. Seeger mudou o título da canção para "We shall overcome" e, junto com Guy Carawan, divulgou a música com tanta intensidade a ponto de tornar-se o tema do movimento pelos direitos civis nos Estados Unidos.

De acordo com a versão mais aceita, uma das grevistas de Charleston, Lucille Simmons, teria mudado o estilo do spiritual "I'll be all right", interpretando a canção em um andamento bem mais lento, no long meter style ${ }^{10}$, uma vez que os grevistas manifestantes estavam carregando cartazes e não conseguiriam bater palmas em uníssono. Ela também teria trocado o "eu" pelo "nós", no título e na letra da canção (PHULL, 2008, p.02).

Como era usual em relação às canções folk, a cada interpretação a letra era cantada em acordo aos objetivos do momento, havendo, por isso, diversas versões de "We shall overcome".

Esta canção foi considerada uma union song ao longo da primeira metade do século XX nos Estados Unidos, ou seja, uma canção sindicalista, associada aos movimentos trabalhistas do país, assim como outras canções que na segunda metade do século foram utilizadas nos atos em prol dos direitos civis de afro americanos.

William Roy afirma que, além das igrejas afro americanas sulistas, as três principais organizações que proveram o movimento pelos direitos civis de música foram a Highlander Folk School, os sindicatos e o Partido Comunista, todas com uma herança da tradição musical dos movimentos abolicionistas, o IWW ${ }^{11}$ e canções dos

\footnotetext{
${ }^{10}$ Métrica poética muito utilizada em hinos, na qual há quatro linhas em cada estrofe, com oito sílabas em cada linha e com o padrão de rimas A B A B.

11 Workers os the World - IWW, organização anarco sindicalista fundada em 1905 e que em 1909 já havia publicado um cancioneiro de cunho revolucionário que teve inúmeras reedições, o I.W.W. Songs, conhecido como The Little Red Songbook. Os Wobblies, como ficaram conhecidos seus membros, ao invés de utilizarem o repertório revolucionário internacional, compuseram suas próprias canções militantes, pautados em suas experiências nacionais e no repertório de canções populares largamente conhecidas nos Estados Unidos, incluindo muitas canções folk. Todavia, as teorizações e apologia das tradições folclóricas enquanto significativas contribuições à militância política, só se daria com os comunistas, a partir dos anos 1930.
} 
partidos políticos. Todavia, o autor chama a atenção para o fato de que não foram sindicalistas que as incluíram no movimento pelos direitos civis, mas sim sujeitos que atuaram como mediadores, como explica no excerto abaixo:

A preponderância das union songs também indica a importância dos mediadores, que ligaram as gerações da Velha Esquerda às organizações dos direitos civis, notavelmente Guy Carawan, que herdou o repertório sindicalista de Zilphia Horton e andava com os remanescentes da Velha Esquerda de Nova Iorque, e Pete Seeger, o maior link entre a People's Song e a Nova Esquerda. Estas canções sindicalistas não apareceram magicamente em Birmingham, Nashville e Albany, mas foram inseridas através de workshops - especialmente na Highlander - redes interpessoais, e ocasionalmente gravações e livros (ROY, 2010, p.192).

Desse modo, pode-se apreender que distintas tradições culturais foram mobilizadas e reformuladas a fim de atenderem as demandas do movimento. Assim, como esclarecem Ron Eyerman e Andrew Jamison, “(...) movimentos sociais tem dado um tipo de foco ou direção política às expressões musicais, carregando a música com uma intensidade e responsabilidade especial” (1998, p.77).

Um dos intérpretes do disco We shall overcome, Bernard Lafayette, integrante do Nashville Quartet, afirmou o seguinte em seu depoimento no livro Everybody says freedom: a history of the Civil Rights Movement in songs and pictures, sobre a presença da música nos ataques sofridos, como os ataques de 20 de maio de 1961 aos freedom riders, em Birmingham:

A canção tem diferentes significados em tempos distintos. Ás vezes você canta sobre os problemas do mundo - "We shall overcome"; às vezes você canta sobre os problemas locais da sua comunidade - "We shall overcome". Mas naquela estação de ônibus era uma prece - uma canção de esperança de que sobreviveríamos e mesmo se nós, daquele grupo, não sobrevivêssemos então nós, enquanto povo, poderíamos vencer (LAFAYETTE In: SEEGER; REISER, 1989, p. 55).

As vozes erguidas em prol dos direitos civis nos Estados Unidos dos anos de 1950 e 1960 foram entoadas em lugares distintos como igrejas, prisões, ocupações e passeatas pelas ruas, praças, espaços públicos e privados, delineando, nestas ocasiões, um repertório de canções que ajudaram a fomentar, mobilizar e manter unido o povo que se levantava contra a segregação e desigualdade racial no país.

Nesse sentido, é possível apreender a existência de um cânon de canções que foram, a partir de 1960, legitimadas via difusão em cancioneiros, livros e discos, 
como o aqui analisado. Tais documentos nos ajudam a entender de que maneira a música foi uma tradição cultural mobilizada por um movimento social, nesse caso, o mais expressivo e influente movimento social estadunidense até então.

\section{Referências}

ABREU, Martha. O legado das canções escravas nos Estados Unidos e no Brasil: diálogos musicais no pós-abolição. Revista Brasileira de História. São Paulo, v. 35, nº 69, p.177-204, 2015.

ARANTES, Mariana Oliveira. Canto em marcha: música folk e direitos civis nos Estados Unidos (1945-1960). 2014. Tese (Doutorado em História) - Departamento de História, Faculdade de História, Direito e Serviço Social, Universidade Estadual Paulista "Júlio de Mesquita Filho", Franca.

AZEVEDO, Cecília; RAMINELLI, Ronald (Org.). História das Américas. Novas Perspectivas. Rio de Janeiro: FGV, 2011.

CARAWAN, Guy; MONTGOMERY GOSPEL TRIO; NASHVILLE QUARTET. We shall overcome. Folkways, FH 5591, 1961. Disco.

CARLIN, Richard. Worlds of sound: the story of Smithsonian Folkways. New York: Smithsonian Books, 2008.

DU BOIS, W. E. B. As almas da gente negra. Tradução de COSTA, José Luis Pereira da. Disponível em: http:/ / www.dacostaex.net/livros/As\%20Almas.pdf. Acesso em: 07, out., 2015.

DUNAWAY, David King. Folk Music, Politics, and the Urge to Sing Out. In: $7^{\circ}$ ENCONTRO INTERNACIONAL DE MÚSICA E MÍDIA, MÚSICA, MEMÓRIA: TRAMAS EM TRÂNSITO, 2011, São Paulo. Anais... São Paulo: Universidade de São Paulo, 2011.

EYERMAN, Ron; JAMISON, Andrew. Music and social movements: mobilizing traditions in the twentieth century.Cambridge: Cambridge University Press, 1998.

GOLDSMITH, Peter D. Making people's music: Moe Asch and Folkways Records. Washington: Smithsonian Institution, 1998.

PHULL, Hardeep. Story behind the protest song: a reference guide to the 50 songs that changed the 20th century. Westport: Greenwood, 2008. 
ROY, William G. Reds, whites, and blues: social movements, folk music, and race in the United States. Princeton: Princeton University, 2010.

SEEGER, Pete; REISER, Bob. Everybody says freedom: a history of the Civil Rights Movement in songs and pictures. New York: W.W. Norton \& Company, 1989. 